combined text-book and laboratory manual. This has been done by including short experimental sections at certain points in each chapter. A useful bibliography of the more important text-books and original papers is included at suitable places throughout the text. The task of compiling a book of this nature is a formidable one for a single author, and no doubt, for this reason, some obvious defects have arisen. In certain sections the facts presented are either completely out of date or they are not, as yet, accepted by the majority of workers. On the whole, however, the material is well presented and should be readily assimilated by the student.

Dr. Salle's book may not readily find a place in the teaching departments of many of the universities in Great Britain, where bacteriology remains an ad hoc subject tacked on as required to larger branches of applied science. We have not, as yet, decided that as a separate branch of biological science it is a subject worthy of a secure position in the university curriculum. Nevertheless, the inclusion of this book in our libraries is to be recommended, if only to illustrate and direct attention to the advanced stage of the teaching of bacteriology, as a separate science, on the American Continent.

Tuberculosis and National Health

By Dr. H. Hyslop Thomson. Pp. xi +260 . (London : Methuen and Co., Ltd., 1939.) 10s. 6d. net.

7 HIS is a valuable contribution to the epidemio1 logy of tuberculosis, by one who has had exceptional opportunities of becoming familiar with the disease in his capacity of medical officer of health and county tuberculosis officer for Hertfordshire, and of former tuberculosis officer or medical superintendent of sanatoria elsewhere. The subjects discussed include the incidence of tuberculosis in man and animals, the types of the disease, etiology and infection, housing and tuberculosis, relation of tuberculosis to milk supply, importance of early detection and treatment, modern treatment and after-care, and tuberculosis and the nursing service.

A bibliography of almost exclusively British and American writers, arranged according to each chapter, is appended.

\section{Prevention of Venereal Disease}

By Dr. Marie Carmichael Stopes. Third edition. Pp. xii +62. (London: Putnam and Co., Ltd., 1939.) $2 s$. $6 d$. net.

7 HIS book is a revised and enlarged edition of a work published under another, though similar, title in 1921, and since reprinted on several occasions. It deals with the causes and prevention of venereal diseases and discusses the relation of promiscuous sex intercourse to their spread. The author, though not medically qualified, has written many popular works on sex subjects, and gives, in this volume, several quotations of the views of medical men on the questions at issue. She describes the technique of disinfection to be applied when risks have been taken, a procedure in which she is a strong believer.

Some of the medical references are not quite up to date, and the new treatment for gonorrhœa, which is one of the most important medical happenings in recent years, is not mentioned.

The psychological effect of statements about the uncertainty of cure has presumably been considered by the author; but those who have had experience of the phobias which the victims of these diseases are apt to develop would have preferred that vague assertions of this kind should not have been made.

Nevertheless, this book does a useful service in directing attention to diseases the causes and effects of which should be known to all young people, and concerning which there is still a denial of publicity through ordinary channels.

\section{MetalluRgy}

The Physical Examination of Metals

By Bruce Chalmers. Vol. 1: Optical Methods. Pp. viii $+181+4$ plates. (London : Edward Arnold and Co., 1939.) 14s. net.

NETHODS which have not yet become part of 1 the metallurgist's technique are the subject of this book. After a short introductory chapter on the properties of light, the applications of geometrical optics are discussed with special reference to the examination of metal surfaces, the measurement of reflectivity and the optical properties of thin films. Two chapters are then devoted to wave optics, under the headings of interference and diffraction phenomena. The principles of parallel and inclined plate interferometers are explained, and some applications, reaching a pinnacle of elegance in the author's precision extensometer, are described. Methods of examining films and coatings on metals involving interference colours and fringes are also described. Applications of diffraction phenomena include the measurement of fine meshes and particle size of powders, and an explanation of microscope resolving power.

Chapter $\mathrm{v}$ is devoted to the theory of polarized light, the experiments of Tronstad and of Lavery, and microscopical technique for identifying inclusions and determining state of strain. The final chapter deals with two optical methods in which the source of the light is the point of interest, namely, radiation pyrometry and spectrography. There is more 'meat' in this book than is revealed by a casual survey; the author has evidently taken great care in his selection of material, and, with his gift of clear expression, has enabled the average metallurgist to absorb quite a lot of physics without too much labour. Incidentally, one is still permitted to believe in an 'aether' for the purpose of the book.

\section{Principles of Metallography}

By Prof. Robert S. Williams and Prof. Victor 0. Homerberg. (International Chemical Series.) Fourth edition. Pp. ix +339. (New York and London: McGraw-Hill Book Co., Inc., 1939.) 23s.

7 HE popularity of this book is explained by the 1 way in which the authors have succeeded in combining clarity with brevity. The treatment of 